\title{
Evaluation of Total Daily Dose and Glycemic Control for Patients Taking U-500 Regular Insulin Admitted to the Hospital
}

\author{
Andrew O/ Paulus \\ San Antonio Military Medical Center \\ Jeffrey A. Colburn \\ San Antonio Military Medical Center \\ Mark W. True \\ San Antonio Military Medical Center \\ Darrick J. Beckman \\ San Antonio Military Medical Center \\ Richard P. Davis \\ San Antonio Military Medical Center
}

See next page for additional authors

Tell us how you used this information in this short survey.

Follow this and additional works at: https://digitalcommons.unmc.edu/com_hosp_articles

\section{Recommended Citation}

Paulus, Andrew O/; Colburn, Jeffrey A.; True, Mark W.; Beckman, Darrick J.; Davis, Richard P.; Wardian, Jana L. PhD; Graybill, Sky D.; Folaron, Irene; and Lewi, Jack E., "Evaluation of Total Daily Dose and Glycemic Control for Patients Taking U-500 Regular Insulin Admitted to the Hospital" (2016). Journal Articles: Hospital Medicine. 29.

https://digitalcommons.unmc.edu/com_hosp_articles/29

This Article is brought to you for free and open access by the Hospital Medicine at DigitalCommons@UNMC. It has been accepted for inclusion in Journal Articles: Hospital Medicine by an authorized administrator of DigitalCommons@UNMC.For more information, please contact digitalcommons@unmc.edu. 


\section{Authors}

Andrew O/ Paulus, Jeffrey A. Colburn, Mark W. True, Darrick J. Beckman, Richard P. Davis, Jana L. Wardian PhD, Sky D. Graybill, Irene Folaron, and Jack E. Lewi 


\title{
EVALUATION OF TOTAL DAILY DOSE AND GLYCEMIC CONTROL FOR PATIENTS TAKING U-500 REGULAR INSULIN ADMITTED TO THE HOSPITAL
}

\author{
Andrew O. Paulus, MD ${ }^{1}$; Jeffrey A. Colburn, $M D^{1}$; Mark W. True, $M D^{1}$; \\ Darrick J. Beckman, MD", Richard P. Davis, MD ${ }^{1}$; Jana L. Wardian, PhD'; \\ Sky D. Graybill, $M D^{1}$; Irene Folaron, $M D^{1}$; Jack E. Lewi, $M D^{1}$
}

\begin{abstract}
Objective: Patients using U-500 regular insulin are severely insulin resistant, requiring high doses of insulin. It has been observed that a patient's insulin requirements may dramatically decrease during hospitalization. This study sought to systematically investigate this phenomenon.

Methods: We performed a retrospective chart review of patients with U-500 insulin outpatient regimens who were admitted to the San Antonio Military Medical Center over a 5-year period. Each patient's outpatient total daily dose (TDD) of insulin was compared to the average inpatient TDD. The outpatient estimated average glucose (eAG) was calculated from the glycated hemoglobin (HbA1c) and compared to the average inpatient glucose.

Results: There were 27 patients with a total of 62 separate admissions. The average age was 64.4 years, with a mean body mass index of $38.9 \mathrm{~kg} / \mathrm{m}^{2}$ and eAG of $203 \mathrm{mg} /$ dL (HbAlc, 8.7\%, $71.6 \mathrm{mmol} / \mathrm{mol})$. All patients were converted from U-500 to U-100 upon admission. The average inpatient TDD of insulin was 91 units, versus 337 units as outpatients $(P<.001)$. Overall, $89 \%$ of patients received $\leq 50 \%$ of their outpatient TDD. The average inpatient glu-
\end{abstract}

Submitted for publication April 13, 2016

Accepted for publication June 9, 2016

From the ${ }^{1}$ Endocrinology Service, Department of Medicine, San Antonio Military Medical Center, Fort Sam Houston, Texas, and ${ }^{2}$ Diabetes Center of Excellence, Wilford Hall Ambulatory Surgical Center, Joint Base San Antonio, Lackland, Texas.

Address correspondence to Dr. Andrew O. Paulus, Endocrinology Service, Department of Medicine, San Antonio Military Medical Center, Joint Base San Antonio, Fort Sam Houston, TX 78234.

E-mail: andrew.paulus@us.af.mil.

Published as a Rapid Electronic Article in Press at http://www.endocrine practice.org on June 30, 2016. DOI: 10.4158/EP161355.OR

Copyright (C) 2016 AACE.

AACE makes no claims to U.S. Government work. cose was slightly higher than the outpatient eAG, $234 \mathrm{mg} /$ $\mathrm{dL}$ versus $203 \mathrm{mg} / \mathrm{dL}(P=.003)$.

Conclusion: U-500 insulin is prone to errors in the hospital setting, so conversion to U-100 insulin is a preferred option. Despite a significant reduction in insulin TDD, these patients had clinically similar glucose levels. Therefore, patients taking U-500 insulin as an outpatient can be converted to a U-100 basal-bolus regimen with at least a 50\% reduction of their outpatient TDD. (Endocr Pract. 2016;22:1187-1191)

\section{Abbreviations:}

$\mathbf{B G}=$ blood glucose; $\mathbf{e A G}=$ estimated average glucose; HbA1c = glycated hemoglobin; NPO = nil per os; SPSS = Statistical Package for the Social Sciences; TDD $=$ total daily dose

\section{INTRODUCTION}

$\mathrm{U}-500$ regular insulin is 5 times more concentrated than U-100 regular insulin and is generally used in patients with severe insulin resistance requiring greater than 200 units of insulin per day (1). It was first introduced as concentrated bovine U-500 insulin in 1952 by Eli Lilly and subsequently replaced by porcine U-500 insulin in 1980 . The current formulation of U-500 human insulin (Humulin R U-500) was introduced in 1997 and is currently the only formulation available $(2,3)$. The number of patients treated with U-500 insulin has significantly increased in recent years, as shown by a $97 \%$ increase in prescriptions written between August 2008 and September 2010. The increase mirrors the epidemics of obesity and type 2 diabetes mellitus $(2,3)$. These severely insulin-resistant patients require high doses of insulin to achieve glycemic control.

With the rise in U-500 insulin use, the number of patients taking this medication who are admitted to hospitals has also increased. The use of U-500 insulin in the hospital has created some challenges to effective care. There are no formal published guidelines on inpatient manage-

This material is protected by US copyright law. To purchase commercial reprints of this article, visit www.aace.com/reprints. For permission to reuse material, please access www.copyright.com or contact the Copyright Clearance Center, Inc. (CCC). 
ment for patients treated with U-500 insulin. The literature is sparse on how outpatient U-500 insulin regimens should be managed during hospitalization. Concentrated U-500 insulin is considered a high-alert medication for use in hospitals (4). The American Society of Health-System Pharmacists and the Institute for Safe Medication Practices (ISMP) have strict recommendations regarding U-500 insulin use in the hospital, and some recommend against its routine use in the inpatient setting even in patients being prescribed U-500 insulin as an outpatient $(1,5)$.

Use of U-500 insulin in the inpatient setting is prone to errors at every step of the prescribing, storing, dispensing, and administration process $(4,5)$. Some hospitals do not carry U-500 on formulary or have policies against its use (6). Lack of a U-500 calibrated syringe is a large source of confusion among both patients and physicians. U-500 insulin is either prescribed as units on a U-100 insulin syringe or milliliters on a tuberculin syringe (5). The ISMP recommends U-500 insulin vials never be stored on the hospital floor and stored separately from other insulins in the pharmacy to avoid accidental use $(4,5)$. The pharmacokinetics of U-500 insulin include both a bolus effect and a basal effect, with a duration of action of 11.5 hours (4). This places hospitalized patients at risk for hypoglycemia because they frequently miss meals for test and procedures. This has led some physicians to recommend against routine use of U-500 insulin in the inpatient setting even on patient's prescribed U-500 insulin as an outpatient (1). If U-500 insulin is to be used during a hospitalization, it has been recommended that it be prescribed by a multidisciplinary team with multilayered safeguards to prevent dosing errors and adverse outcomes $(4,5,7)$.

In our institution, it has been anecdotally observed that a patient's insulin requirements may be dramatically less upon admission to the hospital. To our knowledge, there is only one published study on U-500 insulin in hospitalized patients (8). Therefore, we sought to systematically investigate this observation in our facility.

\section{METHODS}

Institutional Review Board approval was obtained. We performed a retrospective chart review of patients treated with U-500 insulin as outpatients and admitted to the San Antonio Military Medical Center from July 2009 to July 2014. Inclusion criteria included patients between 18 and 89 years old with a hospital stay greater than 24 hours and treated with U-500 insulin at the time of admission. Patients were excluded if their outpatient U-500 insulin dose could not be determined. Data collection included the outpatient total daily dose (TDD) of insulin, most recent glycated hemoglobin (HbAlc), age, height, and weight. Once the patient was admitted, the TDD of insulin was recorded from the electronic medication administration record. Data collection began at midnight after the day of admission, and hospital days were defined as the 24-hour period from midnight to midnight. Data were only collected on hospital days that patients spent the entire 24-hour period from midnight to midnight in the hospital. Partial days, like the day of admission and the day of discharge, were not included because the TDD of insulin and glucose values could not be accurately determined. The type of insulin (long versus short acting) was demarcated in the electronic medical record but was not collected as part of this study; rather, only the total amount of insulin given was collected in accordance with the study's aims. The average daily glucose was calculated from the point-of-care glucose levels recorded in the medical chart. The admitting team decided what insulin regimen to start, as there was no standardized insulin protocol for U-500 insulin patients at our institution.

Each patient's outpatient TDD of insulin was compared to the average inpatient TDD. The patient's outpatient estimated average glucose (eAG) was calculated from the $\mathrm{HbAlc}$ and compared to the average inpatient glucose level during their admission. Statistical Package for the Social Sciences (SPSS) 19 software was used to analyze the data. A paired $t$ test was used to compare outpatient versus inpatient TDD of insulin and outpatient versus inpatient glucose.

\section{RESULTS}

There were 75 patients admitted to the hospital that were prescribed U-500 insulin at some point during the study's 5-year timeframe. However, only 27 patients qualified for analysis based on inclusion/exclusion criteria. Twenty-eight patients were not using a U-500 insulin regimen at the time of their admission, whereas 15 patients had stays less than 24 hours, and 5 patients had undeterminable outpatient insulin doses. Data were collected on the 27 qualifying patients, with a total of 62 separate admissions (Table 1). There were 8 female and 19 male patients. The mean age was 64.4 years, with a mean body mass index (BMI) of $38.9 \mathrm{~kg} / \mathrm{m}^{2}$ and mean eAG of $203 \mathrm{mg} / \mathrm{dL}$ (normal, 74 to $109 \mathrm{mg} / \mathrm{dL}$ ) (HbA1c, $8.7 \%$ [normal, 4.6 to $5.6 \%$ ]; $71.6 \mathrm{mmol} / \mathrm{mol}$ [normal, 26.8 to $37.7 \mathrm{mmol} / \mathrm{mol}$ ]). The mean length of stay was 4 days.

All patients were converted from U-500 to various U-100 insulin regimens upon admission to include insulin drip, basal-bolus regimen, or sliding-scale-only regimen. Three patients received at least one dose of U-500 during their stay, and it appeared from the chart review they were switched to a U-100 insulin regimen because of difficulty in obtaining U-500 insulin on the inpatient service. There was no protocol or standardized conversion for these patients, so their inpatient insulin regimen was determined by the admitting team's preference.

The average inpatient TDD of insulin was 91 units, significantly lower than the average outpatient TDD of 337 


\begin{tabular}{|c|c|c|c|}
\hline \multicolumn{4}{|c|}{$\begin{array}{l}\text { Table } 1 \\
\text { Patient Demographics, Insulin Doses and Glucose }\end{array}$} \\
\hline & Total & Men & Women \\
\hline Patients & 27 & 19 & 8 \\
\hline \multirow[t]{2}{*}{ Admissions } & 62 & 40 & 22 \\
\hline & Mean & Minimum & Maximum \\
\hline Age (years) & 64.4 & 47 & 85 \\
\hline BMI $\left(\mathrm{kg} / \mathrm{m}^{2}\right)$ & 38.9 & 26.4 & 54.7 \\
\hline HbA1c $(\%)$ & 8.7 & 5.7 & 15.5 \\
\hline $\mathrm{HbA1c}(\mathrm{mmol} / \mathrm{mol})$ & 71.6 & 38.8 & 145.9 \\
\hline Estimated average glucose $(\mathrm{mg} / \mathrm{dL})^{\mathrm{a}}$ & 203.5 & 117 & 398 \\
\hline Outpatient TDD insulin (units of insulin) & 337.6 & 100 & 1,250 \\
\hline Outpatient units of insulin per $\mathrm{kg}$ & 3.0 & 0.8 & 11.8 \\
\hline Length of stay (days) & 4.0 & 1 & 16 \\
\hline Average inpatient BG (mg/dL) & 234.4 & 97 & 450 \\
\hline Average inpatient TDD Insulin (units of insulin) & 91.0 & 8 & 400 \\
\hline Inpatient units of insulin per $\mathrm{kg}$ & 0.8 & 0.1 & 3.7 \\
\hline \multicolumn{4}{|c|}{$\begin{array}{l}\text { Abbreviations: } \mathrm{BG}=\text { blood glucose; } \mathrm{BMI}=\text { body mass index; HbA1c = glycated hemoglobin; } \\
\text { TDD = total daily dose. } \\
\text { a Calculated from HbA1c. }\end{array}$} \\
\hline
\end{tabular}

units $(P<.001)$, representing $27 \%$ of the outpatient insulin dose. The median values were lower with an inpatient TDD of 65 units and outpatient TDD of 270 units but with a similar reduction of insulin received, at $24.1 \%$ of the outpatient dose. Average inpatient insulin dose by weight was 0.8 units $/ \mathrm{kg}$ of body weight versus the outpatient insulin dose of 3.0 units $/ \mathrm{kg}(P<.001)$. Overall, $89 \%$ of patients received $\leq 50 \%$ of their outpatient TDD while in the hospital. The average inpatient glucose was slightly higher than the outpatient eAG, $234 \mathrm{mg} / \mathrm{dL}$ versus $203 \mathrm{mg} / \mathrm{dL}(P$ $=.003)$. Figure 1 shows the change in the TDD of insulin over the course of the first 5 days of hospitalization. The percent of outpatient TDD started out at $100 \%$ when the patient was an outpatient and dropped to $24.5 \%$ on the first day of admission. As the insulin was titrated, it peaked at $36.2 \%$ of outpatient TDD on day 4 and decreased to $29.2 \%$ on day 5. During this time, the patient's average glucose increased from the outpatient eAG of $203 \mathrm{mg} / \mathrm{dL}$ to 242.5 $\mathrm{mg} / \mathrm{dL}$ on day 1 and gradually decreased as the insulin was titrated up and was $195.8 \mathrm{mg} / \mathrm{dL}$ on day 5 .

Data pertaining to a total of 245 hospital days were collected. The average glucose was $<180 \mathrm{mg} / \mathrm{dL}$ on 86 $(35.1 \%)$ of those days. During those days, patients received an average of $30.0 \%$ of their outpatient TDD of insulin. Finally, there was no difference in the amount of insulin received based on the patients' level of glycemic control prior to admission. Patients with an HbA1c <8\% (63.9 $\mathrm{mmol} / \mathrm{mol}$ ) required $29 \%$ of their outpatient TDD, while patients with an $\mathrm{HbA} 1 \mathrm{c} \geq 8 \%(63.9 \mathrm{mmol} / \mathrm{mol})$ required a similar $27 \%$ of their TDD.

\section{DISCUSSION}

The use of U-500 regular insulin has increased in recent years due to a rise in severe insulin resistance, defined as requiring greater than 200 units of insulin per day $(2,3)$. When patients taking U-500 insulin as an outpatient require hospitalization, there are no formal guidelines or consensus among physicians on what insulin regimen or dose reduction should be used. Because of this lack of guidance, patients using U-500 insulin in our institution were prescribed a wide range of insulin regimens and starting doses. These patients routinely had their TDD of insulin reduced upon admission, although there was no reasoning given in the chart as to how the admitting team determined the starting inpatient insulin dose. We suspect that a large factor in the dose reduction came from physician unfamiliarity with U-500 insulin and uneasiness prescribing extremely high doses of insulin. On a survey of physicians and nurses performed at our institution, $47 \%$ of respondents reported being "very uncomfortable" with U-500 insulin use (9). We sought to evaluate and describe the inpatient insulin requirements in our hospital so as to provide a framework for insulin regimen recommendations for future hospitalized U-500 patients and research studies. 


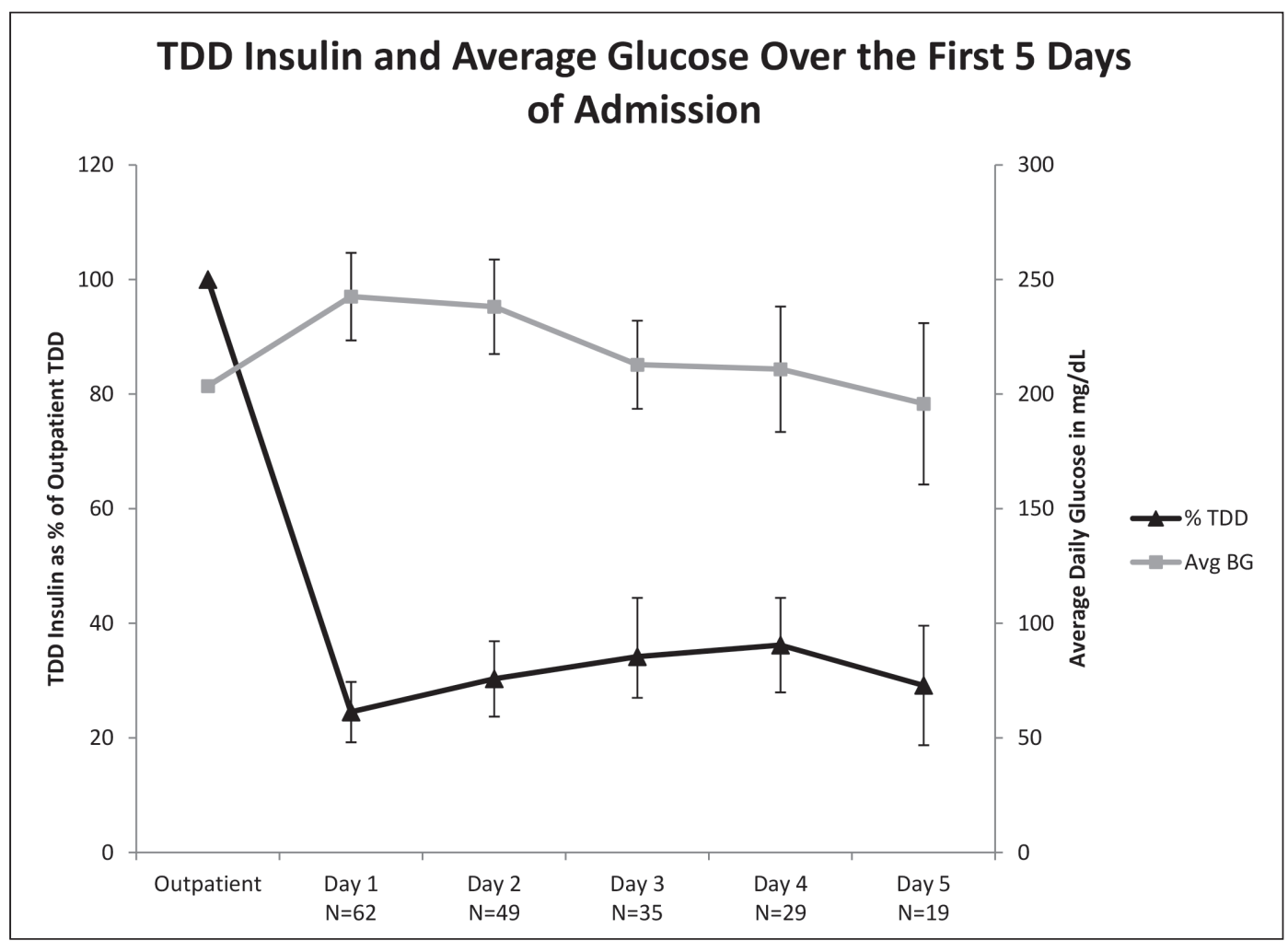

Fig. 1. Outpatient total daily dose (TDD) of insulin and estimated average glucose (calculated from glycated hemoglobin) compared to percent of outpatient TDD of insulin and inpatient average blood glucose (BG) over the first 5 days of hospital admission.

All patients in this study received a lower TDD of insulin as an inpatient than as an outpatient with $89 \%$ of patients requiring $\leq 50 \%$ of their outpatient TDD. The dose reduction in these patients was even more striking knowing that hospitalized patients can have increased insulin requirements that include, but are not limited to, acute stress, parenteral and enteral nutrition, corticosteroid use, and medical illnesses that contribute to hyperglycemia, such as pancreatitis (1). Possible factors for decreased insulin requirements in these patients include controlled hospital diet, nil per os (NPO) status, and strict adherence to timing and dose of insulin injections by nursing staff. We suspect that the change in insulin requirement is predominantly driven by decreased in caloric intake, as U-500 insulin patients tend to have obesity, and patients in this study had an average BMI of $38.9 \mathrm{~kg} / \mathrm{m}^{2}$. This is supported by a recent case report in which a patient on U-500 insulin had a large reduction in insulin after making dietary changes prior to bariatric surgery (10). The authors describe a patient on 320 units of U-500 insulin daily who was converted to U-100 detemir and lispro 10 days prior to surgery. The patient was instructed to dramatically reduce her caloric intake, and her glucose levels and insulin use were recorded. During the final 2 days before surgery, the patient was on a clear-liquid diet and discontinued all insulin injections. Blood glucose was consistently between 100 and $140 \mathrm{mg} / \mathrm{dL}$ during these 2 days when the patient was not injecting any insulin (10). Our study did not correct for potential causes of increased or decreased insulin requirements. Instead, it quantified the overall insulin requirements of U-500 patients after hospital admission.

To our knowledge, only one other study, by Tripathy and Lansang (8), has studied U-500 insulin in hospitalized patients. Their study was a retrospective chart review of 61 admitted patients who had been using U-500 insulin at outpatient. They categorized the patients into 2 groups. One group continued U-500 insulin while in the hospital, and the other group was switched to U-100 insulin. The U-500 group remained on $85 \%$ of their outpatient TDD (200 units TDD in hospital and 235 units TDD prior to hospitalization), but the group switched to U-100 only required $35 \%$ of their outpatient TDD (35 units TDD in hospital and 100 units TDD prior to hospitalization). The average glucose between the 2 groups was not statistically significant (237.6 mg/dL for the U-500 group and $207.9 \mathrm{mg} / \mathrm{dL}$ for the U-100 group; $P=.480$ ). Their study also found a higher incidence of hypoglycemia in the U-500 group (8).

Our findings of U-500 insulin patients receiving $27 \%$ of their outpatient TDD after being switched to a U-100 insulin regimen is similar to the Tripathy study group that was switched to a U-100 insulin regimen and received $35 \%$ of their outpatient TDD. It is unclear why their group that continued on U-500 required $85 \%$ of their outpatient TDD. One could speculate that perhaps they required more insu- 
lin because their outpatient TDD was higher (235 units of insulin in the U-500 group versus 100 units insulin in the U-100 group) and were therefore more insulin resistant. However, the patients in our study had an average TDD of insulin of 337.6 units and received much less than $85 \%$ of their outpatient TDD of insulin. While there are algorithms on converting U-100 insulin patients to U-500 insulin, there is a lack of information on converting U-500 insulin to U-100 insulin as an outpatient as well, so perhaps part of the difference could be due to the pharmacodynamics of U-500 insulin (10).

Limitations of this study include its small sample size, lack of hypoglycemia data due to only average daily glucose values being obtained, and the retrospective nature of the study. Patients were predominantly admitted to the internal medicine service with moderate acuity, but the reason for admission, admitting service, and percentage of time patients spent NPO were not collected. Use of eAG calculated from the HbA1c is another limitation because it is not directly equivalent to mean glucose calculated from point-of-care glucose levels. However, since outpatient fingerstick glucose readings were unavailable, we felt this was the best approximate for outpatient glucose control compared to inpatient glucose control. The average inpatient glucose of $234 \mathrm{mg} / \mathrm{dL}$ was above the American Diabetes Association (ADA) Standards of Medical Care in Diabetes goal of 140 to $180 \mathrm{mg} / \mathrm{dL}$ in hospitalized patients (11), so the patients in our study may have needed higher insulin doses than they received. However, the patients in our study had an average HbA1c of $8.7 \%(71.6 \mathrm{mmol} / \mathrm{mol})$ (corresponding to an outpatient eAG of $203.5 \mathrm{mg} / \mathrm{dL}$ ), so they achieved clinically similar glycemic control while hospitalized on a much lower insulin dose. Also, on $35.1 \%$ of the hospital days, the average glucose was at the ADA recommended goal of less than $180 \mathrm{mg} / \mathrm{dL}$ while patients were receiving only $30.0 \%$ of their outpatient TDD of insulin. In Figure 1, the change in the patients TDD of insulin and average glucose from baseline are graphed over the first 5 days of admission. It shows the glucose spikes on the first day, with an average glucose of $242.5 \mathrm{mg} / \mathrm{dL}$ and patients receiving $24.5 \%$ of their outpatient TDD of insulin. Over the following days, the amount of insulin increased as the insulin was titrated up and the glucose level slowly trended down. The amount of insulin received peaked at $36.2 \%$ of their outpatient TDD on day 4. By day 5, the average glucose was lower than their outpatient eAG $(195.8 \mathrm{mg} / \mathrm{dL}$ versus $203.5 \mathrm{mg} / \mathrm{dL}$ ), and patients were on average receiving $29.2 \%$ of their outpatient TDD of insulin.

U-500 insulin dosing is prone to errors on multiple levels in the hospital setting, and many physicians are unfamiliar with its use, so conversion to U-100 insulin is a safer and preferred option. Despite a significant reduction in insulin TDD, the patients in our study had clinically similar glucose levels compared to their outpatient eAG. This study provides a general idea of insulin requirements in U-500 patients that are hospitalized and a starting point for future patients and studies. Since the average inpatient TDD of insulin was $27 \%$ of their outpatient TDD, and $89 \%$ of admissions received $\leq 50 \%$ of their patient TDD, we propose that it is reasonable to convert U-500 patients to U-100 insulin on admission, with a dose reduction of at least $50 \%$ of their outpatient TDD. The patient's outpatient glucose control, reason for admission, NPO status, admission glucose, and corticosteroid use should be taken into consideration by the admitting physician and the patients' glucose levels should be closely monitored and insulin titrated as needed to maintain adequate glucose control.

\section{CONCLUSION}

Patients taking U-500 insulin as an outpatient can be converted to a U-100 basal-bolus regimen, with at least a $50 \%$ reduction of their outpatient TDD upon hospital admission. Further prospective trial data are needed to best evaluate the ideal approach to this situation.

\section{DISCLOSURE}

The authors have no multiplicity of interest to disclose. The views expressed in this manuscript are those of the authors and do not represent official views of the U.S. Air Force, Department of Defense, or U.S. government.

\section{REFERENCES}

1. Larsen J, Goldner W. Approach to the hospitalized patient with severe insulin resistance. J Clin Endocrinol Metab. 2011;96:26522662.

2. de la Peña A, Riddle M, Morrow LA, et al. Pharmacokinetics and pharmacodynamics of high-dose human regular U-500 insulin versus human regular U-100 insulin in healthy obese subjects. Diabetes Care. 2011;34: 2496-2501.

3. Lane WS, Cochran EK, Jackson JA, et al. High-dose insulin therapy: is it time for U-500 insulin? Endocr Pract. 2009;15:7179.

4. Segal AR, Brunner JE, Burch FT, Jackson JA. Use of concentrated insulin human regular (U-500) for patients with diabetes. Am J Health Syst Pharm. 2010;67:1526-1535.

5. Samaan KH, Dahlke M, Stover J. Addressing safety concerns about U-500 insulin in a hospital setting. Am J Health Syst Pharm. 2011;68:63-68.

6. Reutrakul S, Wroblewski K, Brown RL. Clinical use of U-500 regular insulin: review and meta-analysis. J Diabetes Sci Technol. 2012;6:412-420.

7. Monroe PS, Heck WD, Lavsa SM. Changes to medication-use processes after overdose of U-500 regular insulin. Am J Health Syst Pharm. 2012;69:2089-2093.

8. Tripathy PR, Lansang MC. U-500 regular insulin use in hospitalized patients. Endocr Pract. 2015;21:54-58.

9. Colburn JA, True MW. Knowledge gaps in the inpatient use of U-500 regular insulin. In: Program of the Endocrine Society's 96th Annual Meeting and Expo, June 21-24, 2014; Chicago, Illinois. Abstract.

10. Nguyen KV, Weidner JA, Shaw KF, Valdez CA. Converting U-500 regular insulin to insulin detemir and insulin lispro in a patient undergoing dietary changes in preparation for bariatric surgery. Am J Health Syst Pharm. 2016;73:292-297.

11. American Diabetes Association. Standards of medical care in diabetes-2016. Diabetes Care. 2016;38:S99-S104. 